The International Journal of Human Resource Management, Volume 19, Issue 11, 2008, Pages 2041-2056

\title{
The Impact of Bundles of Strategic Human Resource Management Practices on the
} Performance of European Firms

\author{
Paul Gooderham \\ Norwegian School of Economics \& Business Administration (NHH) \\ 5045 Bergen \\ Norway \\ Emma Parry \\ Cranfield School of Management \\ Bedford MK43 0AL \\ United Kingdom \\ Kristen Ringdal \\ Department of Sociology and Political Science, \\ Norwegian University of Science and Technology (NTNU) \\ NO 7491 Trondheim \\ Norway
}




\title{
The Impact of Bundles of Strategic Human Resource Management Practices on the Performance of European Firms
}

\begin{abstract}
The relationship between HRM practices and perceived firm performance was analyzed in 3,281 firms located in European Union countries using data derived from the Cranet data set. A factor analysis of 80 different HRM practices resulted in 15 bundles of HRM practices which were then further categorized as being either "calculative", "collaborative" or "intermediary". While controlling for contingency factors, firm strategy, firm size, market conditions and degree of unionization, as well as controlling for industry and country, the resulting analysis indicates that while five of the six calculative practices and two of the three intermediary practices have a significant impact on performance none of the six collaborative practices has. Significantly it was further noted that the overall effect of HRM on performance was relatively modest.
\end{abstract}




\section{The Impact of Bundles of Strategic Human Resource Management Practices on the Performance of European Firms}

\section{Introduction}

Among human resource practitioners, the term "strategic human resource management" is generally used to signal the view that human resource management (HRM) practices should enhance organisational performance, not least in financial terms (Schuler and Jackson, 2005). Paralleling this, numerous theorists have argued that the human resources of the firm are potentially a powerful source of sustainable competitive advantage for organisations, and have sought to demonstrate that there is a positive relationship between HRM and firm performance (Appelbaum et al. 2000; Arthur, 1994; Pfeffer, 1994; Huselid, 1995; Guest, 1997; Ferris et al., 1999). However, since the concept of strategic HRM was launched in the mid 1970s, there has been uncertainty as to which of the many "high performance" HRM practices (Delany et al., 1989) actually facilitate superior performance (Ferris et al., 1999; Collins and Smith, 2006).

Authors such as Walton (1985), Arthur (1994), Gooderham et al. (1999) have proposed that one can distinguish between two generic categories of HRM practices. On the one hand there are those practices that are referred to as control or calculative HRM practices such as performance-related pay that emphasize quantifiable exchanges between the firm and the employer. On the other hand, there are those practices that are labelled commitment-based or collaborative such as employee strategy briefings that aim to foster employer-employee mutuality of interest. It is important to note that the calculative and collaborative HRM categories are not intended to embrace each and every HRM practice. Thus there are HRM practices that fall outside these two categories. Without intending to suggest a continuum between calculative and collaborative HRM (Gooderham, et al., 1999) we will refer to those 
practices that cannot be readily categorized in terms of the two generic categories as “intermediary" practices.

The primary aim of this study is to compare the impact of bundles of both calculative and collaborative HRM practices on firm performance. Thus a consideration of the impact of "intermediary" practices is largely of secondary interest to this paper.

Past research in this area has mostly focused on the US rather than Europe. The exceptions have invariably focussed on single European countries. Thus Archimoles (1997) examined the relationship between HRM and organisational performance in French organisations, Boselie, Paauwe and Jansen (2001) investigated the association between HRM practices and firm performance in the Netherlands and Guest et al. (2003) investigated the association between HRM and corporate performance in the UK. One study that has examined a number of European countries is that of Stavrou and Brewster (2005), but this study treated Europe as one homogeneous setting and did not take into account national differences. Thus studies that include the broader European setting in the sense of a variety of different European settings have to date not featured in HRM-performance research. This study aims at addressing this dearth by spanning firms located across 16 European Union (EU) countries across a range of industries.

To summarize, the significance of this paper is three-fold. First, it addresses the key question within strategic HRM, i.e. the extent to which HRM practices influence firm performance. Second, it does this on the basis of a comprehensive range of both calculative and collaborative bundles of practices. Third, it draws on firm data that spans a wide-range of European countries. As such this paper constitutes a major testing of the core notion within strategic HRM. 


\section{HRM and Firm Performance}

There is a growing literature on the impact of HRM practices on organisational performance. This literature is commonly underpinned by the resource-based view of the firm with its emphasis on gaining sustainable competitive advantage by means of effective and efficient utilisation of the resources of the organisation (Paauwe, 2004). That is successful organisations are those which have acquired and utilised valuable, rare, inimitable and nonsubstitutable resources, including human resources (Barney 1991, 1995; Barney and Wright, 1998). Thus for example Wright and McMahan (1992) discussed the importance of human resources in the creation of competitive advantage, while Wright, McMahan and McWilliams (1994) suggested that while human resources are always a potential source of sustained competitive advantage not all organisations have the ability to systematically develop these through the use of HRM practices. Similarly Huselid (1995) and Pfeffer (1995) have used the resource-based view as a basis for examining the impact of human resource development on firm performance. Summarizing, Guthrie (200:181) noted that "the common theme in the literature is an emphasis on utilising a system of management practices giving employees skills, information, motivation and latitude and resulting in a workforce that is a source of competitive advantage."

The literature on HRM and performance can be divided into three main kinds of theories (Delery and Doty, 1996), universalistic, contingency and configurational. We will initially focus on the universalistic and configurational approaches, attending to the contingency approach in the next section. Universalistic theories, such as those developed by Huselid, (1995), Osterman (1994) and Pfeffer (1994) are concerned with "best practice" and work on the underlying assumption that there is an association or linear relationship between HRM practices and organisational performance, that "best practices" are generalizable and that organisational success is best measured in terms of financial performance. Universalistic 
theorists have in general employed individual HRM practices and have analyzed the relationship between individual HRM activities and performance. An overview of these studies can be found in Boselie, Paauwe and Jansen (2001). One notable example is Pfeffer (1994) who identified a series of sixteen HRM practices that he argues will lead to improved performance, including employment security, selectivity in recruiting, high wages, incentive pay, employee ownership, information sharing, participation and empowerment and training and skill development in firms in general. Another is Delaney and Huselid (1996) who examined and generally confirmed the impact of seven "progressive" HRM practices, including training and incentive compensation, on organizational performance.

However as Alcázar et al., 2005 point out there are also universalistic approaches in which more than one HRM practice is combined thereby building so-called "High Performance Works Systems". One example is Guthrie (2001) who measured companies' use of high involvement work practices and found that utilising these can enhance organisational competitiveness. Guest et al. (2003) in their study of HRM in UK companies identified 48 single, HRM practices drawing these primarily from the existing "high-commitment" HRM literature. These items were grouped into "nine main areas of HRM" (Guest et al., 2003: 297) including training and development and appraisal. Initial factor analysis of these nine aggregate HRM practices, "revealed no coherent factors" (p.301). Therefore to create a measure of the overall human resource system, a measure was derived by combining mean scores across the nine practices. Guest et al. (2003) found partial support for an association between the greater use of HRM practices and lower reported labour turnover and for higher profit per employee but found no support for an association between HRM and higher productivity. Huselid's (1995) approach also involved the combination of HRM practices, combining a number of practices into "High Performance Works Systems". Factor analyzing 13 HRM practices he identified two factors, "employee skills and organizational structures" 
and "employee motivation". He found that these were significantly related to turnover, organizational productivity and financial performance. In short, within the universalistic approach to HRM and performance it is becoming common to group or combine practices in order to create more coherent explanations of the HRM-performance link.

Central to the configurational perspective, is the argument that the impact of HRM on organisational performance is dependent on the adoption of an effective combination of HRM practices, often referred to as HRM bundles (MacDuffie, 1995). Thus the configurational approach has as its basis that maximizing firm performance is dependent on the bundling together of interrelated elements of HRM practices in an internally consistent manner. Configurational theories propose that the relationship between HRM and performance involves complex interactions between bundles of HRM activities and outcomes (Arthur, 1994; MacDuffie, 1996). Such bundles of complementary practices are held to produce substantially greater performance effects than individual HRM practices (Ichniowski et al., 1997). Ichniowski et al. (1997) explained that interaction effects among HRM policies are important determinants of productivity so firms realise the largest improvements in productivity by adopting bundles or clusters of complementary practices rather than making changes to single practices. Although there are firm-specific variants of the configurational approach, at its simplest "the configurational argument is based on the assumption that (HRM bundles) are ideal types that are equally effective under all conditions" (Delery and Doty, 1996: 812). Thus for example Kalleberg and Moody (1994) found a tendency for performance enhancing HRM policies and practices to occur together, thereby creating high performance work systems. Likewise both Arthur (1994) and Becker and Huselid (1998) found support for the potential impact of systems or bundles of HRM practices on organisational performance. 
Alcázar et al., 2005 argue that configurational bundles must not be confused with universalistic bundles or systems because while the former consists of holistic patterns of interrelated, synergistic practices, the latter comprises single practices combined in an additive manner. In other words the configurational approach involves more complex typologies of ideal types of HRM systems than found in universalistic approaches. We would argue that this definition is too simplistic and does not always fit with past uses of these two approaches. For example while Guest et al.'s (2003) measure of the overall HRM system is primarily additive, Huselid's (1995) bundles clearly cannot be construed as being additive in their construction. Thus we would argue that certain variants of universalistic bundling and configurational bundling represent closely related approaches that are problematic to distinguish. Groups of HR practices combined additively may clearly be universalistic but the identification of a configurational approach may be more problematic. Terminology aside, the important lesson from this literature is that combining HR practices in a fashion that promotes internal consistency is a better approach to that of simply adding individual effects. In support of this we may note that in their single practices universalistic study Delaney and Huselid (1996), reflecting on Huselid's (1995) use of bundles, stress that examining bundles or clusters of HRM practices is theoretically preferable to studying the effects of individual practices precisely because of an assumption of complementarities or synergies among a firm's HRM practices. That is Delaney and Huselid (1996:955) view "HRM systems rather than individual practices as the appropriate level of analysis when an estimate of the firmlevel effect of HRM practices is desired." This outlook is reiterated by Laursen and Foss (2003:249) who argue that we should, because of potential complementarities between related practices, expect that HRM practices are most conducive to performance when adopted, not in isolation, but as a system of mutually reinforcing practices. 
In other words there is a broad consensus that when assessing the impact of HRM on firm performance a bundling approach is preferable with certain variants of the universalistic bundling approach and the simpler configurational bundling approaches indistinguishable from one another.

\section{Calculative and Collaborative HRM}

When addressing the impact of HRM on firm performance, it is important to observe that HRM has evolved from two distinct conceptions of the link between employee motivation and firm-level outcomes. Walton (1985) suggested that a distinction can be drawn between the control and commitment approaches to HRM. Arthur (1994) argues that the control approach to HRM seeks to improve efficiency by enforcing employee compliance by, for example, basing employee rewards on some measurable criteria. In contrast, commitment approaches to HRM aim to shape attitudes by forging psychological links between organisational and employee goals. This division has been further discussed by Legge (1995).

Empirical studies have largely been confined to assessing the impact of commitmentbased practices on firm performance with a number of authors observing a relationship between commitment-based HRM practices and firm performance (Arthur, 1994; MacDuffie, 1994; Youndt et al., 1996; Bowen and Ostroff, 1996; Perry-Smith and Blum, 2000; Collins and Clark, 2003). More recently Collins and Smith (2006) analyzed the impact of commitment-based HRM practices on organisational performance, and found that an increase in these practices led to an increase in both sales from new products and services and sales growth. As with so many previous studies Collins and Smith only examined the role of commitment-based HRM practices in relation to firm performance and did not include control-based practices. Acknowledging this they argue that there is a need for studies that combine both control and commitment-based HRM practices. One exception is that of Arthur 
(1994) who examined the impact of both control and commitment-based HRM practices.

However, Arthur's study was confined to one single industry, steel mills, in only one country, the United States.

Gooderham et al (1999) has redefined the distinction as being that between calculative HRM practices - aimed at the efficient use of human resources - and collaborative practices aimed at promoting the goals of both employees and employer. The term 'calculative' should not be taken as entirely interchangeable with Walton's 'control' factors. While similar, calculative HRM is defined by GOoderham et alas that designed to promote the efficient use of HRM in general rather than to promote employee compliance. Therefore practices that also encourage efficiency within the HR function such as HR evaluation or training monitoring are also included along with those that promote employee efficiency. The calculative approach is clearly represented in Fombrun et al's (1984) "Michigan Model" that emphasized that superior firm performance is dependent on having in place systems for the regular assessment of individual employees. Associated with and reinforcing these systems are performance rewards and training whose performance-related outcomes are monitored.

The collaborative model of enhancing firm performance is clearly apparent in Beer et al.'s "Harvard Model", which emphasized the need for management to recognise employees as significant stakeholders in the enterprise. At the core of this model is the conception of the centrality of employee influence and the common sense of purpose it engenders for firm performance. Employee influence is contingent on there being processes of mutual influence between management and employees that enable management to comprehend employee interests. Without such processes, employee intrinsic motivation is undermined thereby giving rise to employee resentment and distrust, which results in unwillingness to take 
responsibility for the performance of the firm. Rather than one single system of employee involvement techniques, Beer et al. propose that several approaches, such as employee briefings and work system design, be used. The notion of HRM being used to develop employee commitment is also central to Guest's (1997) theory of normative HRM. By contrast, our study is a full-fledged response to Collins and Smith's call in that we will examine the impact of various bundles of calculative and collaborative HRM practices on firm performance across a variety of industries in the context of a variety of countries. In addition, we will examine the role of a number of contextual factors in this relationship. By including this combination of variables, we are able to make a significant contribution to the literature in this area.

Our first hypothesis draws primarily on the universalistic approach which indicates that both calculative and collaborative HRM practices improve firm performance. However, because we adopt a bundling approach we are also drawing on variants of the configurational approach.

$\mathrm{H}_{1}$ : Both calculative and collaborative bundles of HRM practices will positively impact firm performance.

It has been contended that universalistic theories in particular fail to take into account firm context, a critique that has given rise to the third of Delery and Doty's (1996) approaches, contingency theorization, characterised by the explicit rejection of the universal applicability of HRM practices. For example Schuler and Jackson (1997) argue that in order to be effective, an organisation's HRM policies must be consistent with key aspects of the organisation. Thus the contingency perspective supposes that the relationship between HRM 
practices and performance will vary according to various external and internal influences. One central tenet of contingency theory is that HRM practices can only have a positive impact on performance if they are consistent with an organization's strategy (Alcázar et al., 2005). In addition contingency theorisation has also considered the conditioning impact of a number of external and internal organizational factors. In terms of the former industry membership and firm-level market conditions are regarded as particularly significant (Alcázar et al., 2005). In terms of the latter Schuler and Jackson (1995) argue that a number of internal contextual factors such as firm size and firm strategy must be taken into account. In addition Brewster (1995) argues that union involvement must be taken into consideration.

Thus, in short the contingency approach advocates that our analysis of HRM and performance should include a range of firm internal factors including firm size, level of unionization and generic firm strategy as well the external influence of market conditions. In addition it suggests we should control for possible effects of industry membership.

$\mathrm{H}_{2}$ : The effects of calculative and collaborative bundles of HRM practices will be contingent on both firm internal and external factors.

\section{Method}

Our study is based on cross-sectional data derived from the 1999 Cranet survey of HRM in 16 European countries. The overall strategy of the survey was to mail appropriately translated questionnaires to human resource managers in representative national samples of firms with more than one hundred employees. By firms we mean establishments rather than companies which may for example in the case of conglomerates or holding companies contain more than one firm. Problems in ensuring that the selection and interpretation of topic areas was not 
biased by one country's approach, as well as problems related to the translation of concepts and questions, were largely overcome by close collaboration between business schools located in each country (for a detailed description of the Cranet approach, see Brewster et al, 1996). Although the response rate for the individual countries is relatively low, mostly between 20 and 35 per cent, analyses of previous Cranet surveys suggest that the net sample represents the population in a satisfactory manner (Brewster et al, 1994).

Our sample consists of 3,281 for-profit firms. Table 1 summarizes the country distribution of the sample.

Table 1 About Here

Dependent Variable

The dependent variable, firm performance, is based on a question as to whether gross revenue over the past three years has been well in excess of costs or not. We noted that of the 3,281 firms, 46 percent replied positively to this question. While we acknowledge that this is a subjective evaluation of performance by respondents it is noteworthy that research by Smith, Tyson and Brough (2005) on the Cranet survey data within the UK has substantially validated the results of this question by comparing these responses to what is indicated by objective data on financial performance. Arguably this is unsurprising in that an extensive review by Wall et al. (2004) comparing the validity between objective and self-report measures of firm performance found in all the cases they examined convergent construct validity between the two measures. 


\section{Independent Variables}

The items contained in Cranet are derived from a comprehensive review of the literature on HRM practices that are considered to relate to firm performance. In all, Cranet includes 80 such variables. Our factor analysis using principal component factoring with Varimax Rotation in SPSS 14.0 was based on 61 indicators of HRM practices. The factors were saved using the Anderson-Rubin method in SPSS. As shown in Table 2 a total of 15 factors were identified that together explains about 62 percent of the variance of the 61 indicators. ${ }^{1}$ These factors or HRM bundles are essentially replications of bundles identified by Stavrou and Brewster (2005) in their exploratory analysis of the Cranet data set.

Of these 15 bundles six can clearly be grouped as calculative practices (bundles 1-6) in that they are bundles of practices that can be described as "efficiency seeking" (Gooderham, Nordhaug and Ringdal, 1999, p.510) and involve assessing or rewarding aspects of performance either at the individual or at the group level (e.g. training monitoring could be described as assessing performance at the group level). Seven bundles can be grouped as collaborative practices $(7-11,14)$ in that they involve stimulating employee commitment through cooperation or communication. The results of the PCA also included three bundles career development, wider jobs and downsizing methods - that did not fit clearly within

\footnotetext{
${ }^{1}$ The exploratory factor analysis extracts as many factors as there are variables. Two criteria are used for a parsimonious solution: i) Kaiser's criterion where an eigenvalue of 1 is the cutting point; ii) an examination of the scree plot and making a cut when there is a significant decline in eigenvalue to the next potential factor and the line in the plot flattens. In our case the next potential factor had an eigenvalue of 1.004, just at the Kaiser's criterion, but there is a significant jump in the eigenvalues from around 1.3 for factor 15 and to 1.0 for factor 16. Thus, we decided to accept the 15 factor solution, which is consistent with Stavrou and Brewster (2005). The next step is to examine the pattern of factor loadings. The indicators load strongly on the expected factors with no exceptions as Table 2 shows. The "off-diagonal" factor loadings are omitted from Table 2 for reasons of space. This information is important in evaluating the factor solution. The indicators should ideally show high loadings on the factor, and low loadings on other factors. In fact, there are only two such "off-diagonal" factor loadings that exceed 0.3. One indicator with the highest loading on factor 11 also shows a loading of 0.41 on factor 14 . Another indicator of factor 11 loads 0.33 on factor 14 .
} 
Gooderham et al's definition of calculative and collaborative practices. As they had no common theme they will simply be referred to as 'intermediary' bundles.

Table 2 About Here

In terms of the contingency analysis internal factors are represented by firm size, unionization and two indicators of firm strategy. Firm-size is captured using the natural logarithm of the number of employees in the firm and level of unionization in the firm is measured as a percentage. In regard to firm strategy we have controlled for the importance contra unimportance of two types of generic firm strategy, competing on the basis of cost leadership, that is price, and competing on the basis of differentiation, that is quality (Porter, 1980). In addition we include a key firm external factor, market conditions. This indicator is a dichotomous variable distinguishing firms that are selling into growing markets contra those which are not.

Our analysis also includes two control variables that together provide the broad macrocontext our sample of firms is operating within. The first of these is the country of location. This enables us to control for differences in institutional settings as well as national economic conditions both of which may influence firm performance. Additionally, the data may be seen as clustered by country, and this needs to be controlled for in the design. Therefore, we employ a fixed effects model with dummy indicators for all countries except the UK, which is the reference country. This implies that the levels of firm performance may vary among the countries, but that the effects of the other explanatory variables are assumed to be similar. It is also important to control for variations in firm performance that are ascribable to industry membership. Therefore our second control variable is industry. Our classification distinguishes manufacturing, construction, transport, personnel services and a remaining 
category for all other industries. In our analysis manufacturing serves as the reference category.

Finally, we have also included two control variables that reflect the use of numerical flexibility at the firm-level, i.e. the extent of the use of "part-time" and "temporary" employees. Firms that make extensive use of numerical flexibility are held to be distinct from those that make relatively little use of such arrangements in that while the former are bifurcated into a core-periphery employee groups, the latter constitutes a distinctly more homogenous environment. These differences are viewed as creating the basis for two distinct HRM environments (Atkinson, 1985; Gooderham and Nordhaug, 1997), hence the need to control for this prospect. In order to capture this distinction we have distinguished firms which have at least eleven percent or more part-time employees from those which have less than this, and those firms which have at least eleven percent or more temporary employees from those which have less than this.

\section{Results}

We start our analysis by defining a baseline binary logistic regression model of firm performance with main effects only. The main explanatory variables in this model are the 15 HRM-bundles. In addition the model included a range of contingency firm internal and external factors and controls: firm-size, level of unionization, firm strategy, market conditions, industry membership classification, numerical flexibility, and country of location. In the baseline model, the effects of the HRM-bundles are uniform, in line with the universalistic approach.

The next step was to add interaction effects implied by the contingency approach in order to test hypothesis 2. The large number of HRM-bundles and the weak theoretical 
precision in the contingency approach, pointed to analysing sub-samples by levels of variables derived from the research literature. We tested out the following possible contingency factors; firm size, unionization, strategy on quality, strategy on price, and market conditions. Since strategy on quality and on price was measured by separate variables, we separated split on both quality and price being important for the firm or not.

Finally, in a third step based on the total sample, we added interaction terms for the contingency variables mentioned above and the HRM-bundles that showed the largest effects in the baseline model. The results the additional steps indicated no systematic statistically significant interaction effects in any of these analyses. In effect, the failure to locate systematic interaction effects means that our second hypothesis has to be rejected.

Therefore, we have chosen to only report the results for the baseline model in Table 3, as this model clearly is preferable to the more complex alternatives. The Cox \& Snell pseudo$\mathrm{R}^{2}$ for the baseline model is 0.143 . The remaining pseudo- $\mathrm{R}^{2}$ s shown at the bottom of Table 3 displays the marginal contributions of two of four control variables, industry and country, separately. As neither of the two numerical flexibility controls, part-time and temporary work, had any noteworthy impact on performance their marginal contributions have not been included. In addition to industry and country Table 3 reports the marginal contributions for each of the three sets of variables, the contingency variables, the calculative bundles, and the collaborative and the intermediary bundles. Of these marginal contributions, country of location is the most important. The second most important contribution is that of the calculative bundles, followed by the contingency variables. The collaborative bundles, even when grouped with the intermediary bundles are of relatively little importance. Indeed firm industry membership is as important as the combination of the collaborative and intermediary bundles. 
Going to the main part of Table 3 we note that with the exception of the "Performance related pay" bundle, which is significant at the ten percent level, all of the six calculative bundles of practices have a statistically significant impact on performance at the five percent level. Furthermore, two of the three intermediary bundles of practices are significant at the five percent level. In contrast, none of the six bundles of collaborative practices is statistically significant at the five percent level. Since, the HRM-bundles are measured on the same scale, their coefficients are directly comparable. The comparison shows that the three most important calculative HRM-bundles are profit-sharing, group-bonus, and share-options.

In short we find only partial support for $\mathrm{H}_{1}$. Our results indicate that it is primarily the calculative rather than collaborative bundles of HRM practices that positively impact firm performance

All of the variables derived from the contingency approach in the model, except for level of unionization, have statistically significant effects on firm performance. Both of the two strategy indicators have statistically significant effects, but with different signs. Firms competing on the basis of price lag behind in performance, whereas those who put an emphasis on quality enjoy superior performance. Finally, operating in a growing market enhances firm performance. However, these variables effect performance through their main effects only and thereby do not lend any systematic support for our second hypothesis which implies differential effects of the HRM-bundles by levels of the contingency variables. 


\section{Conclusion and discussion}

The aim of this paper was to examine the core issue within strategic HRM, the extent to which HRM practices have a significant impact on firm performance. In doing so, we have included a far greater range of both calculative and collaborative bundles of practices than previous studies and drawn on different theoretical approaches to the issue of HRM and firm performance. Additionally we have drawn on firm data from a far wider range of countries than earlier studies. Guest (1997: 269) notes that, "the distinctive feature of HRM is its assumption that improved performance is achieved through the people in the organization."

Our findings both support and cast some doubt on the value of HRM for firm performance in the context of Europe in that our findings are different in regard to calculative and collaborative HRM.

While we found that whereas calculative and intermediary HRM bundles, with exceptions, generally have some impact on the performance of European firms, collaborative HRM bundles do not. Thus while our first hypothesis is generally supported in regards to calculative HRM-bundles of practices, it is clearly not for collaborative bundles. In that $\mathrm{H}_{1}$ is derived from the universalistic approach and the simplest forms of the configurational approach these approaches may be considered to have received some measure of support.

The failure to find a relationship between collaborative HRM and performance is in opposition to previous research such as Arthur (1994) and Guest (1997). We have two explanations for this. First, unlike previous studies which have concentrated on the impact of collaborative HRM on performance our study includes a wide range of both calculative as well as collaborative bundles. Second, unlike previous studies we also include a range of contingency variables. 
We also included, as dictated by the results of the Principle Components Analysis, three 'intermediary' bundles. Two of these were significantly related to firm performance. We have therefore added to the previous literature discussing the distinction between calculative and collaborative HRM practices, through our identification of practices that fall outside of this distinction. Our findings suggest that the calculative/collaborative dichotomy may be too simplistic as there are practices that cannot easily be defined as either that have a significant impact on firm performance. More investigation in to how HRM practices may be grouped together by type, and the impact of this on firm performance is needed.

Our second hypothesis, that the effects of the HRM-bundles would be contingent on an interaction with a range of external and internal factors found no support. This does not necessarily mean that the contingency approach is invalidated. More specific theoretical reasoning coupled with appropriate data would provide a firmer conclusion.

Our analysis indicates that for European firms the country of location is a relatively important source of variation in performance. This is unsurprising given the significance of national economic conditions for performance at the firm-level. Additionally, country of location may also reflect the efficacy of national business systems at the firm-level. Future studies should be designed to differentiate between cyclical economic conditions and longterm institutional conditions. This would require a longitudinal design ideally with several time points and combining macro-economic data together with the variables we employ in this study.

Beyond the shortcoming of using cross-sectional data and therefore the difficulty in determining whether performance for example creates more scope for HRM rather than vice versa (Guest et al., 2003) there are other limitations to our findings. One is that contextual factors such as organizational structure and culture have not been controlled for. It has been argued that such contextual factors may render certain practices or groups of practices largely 
irrelevant in terms of firm performance (Ferris et al, 1999). For example if the structure of a firm is a highly hierarchical with a bureaucratic culture, it is unlikely that participative HRM practices would be effective. Another limitation is that it while we do control for generic strategy we do not test for strategic "fit". It has been argued that for HRM practices to impact on performance there must be a particular "fit" between a firm's HRM practices and the firm's competitive strategy (e.g. Wright and Snell, 1991). In other words it may be the case that the bundles of HRM practices firms in our sample are employing have not been sufficiently aligned with their strategic goals. A third limitation is that we do not examine for the horizontal alignment of each firm's various HRM practices. It has been proposed that HRM practices must complement one another to achieve positive performance outcomes (Schuler and Jackson, 1997; Wright and Snell, 1991). Finally, we have not considered the role of possible mediators, such as organizational climate, that may play a decisive role in the HRM-firm performance relationship. For example it has been suggested that HRM practices do not directly impact firm performance but instead contribute to the creation of organizational climates that foster superior performance (Bowen and Ostroff, 2004; Collins and Smith, 2006).

Notwithstanding these limitations, we would argue that our findings do place HRM in a context that is sufficiently broad for us to contend that while certain HRM bundles do have an impact on performance, this should not be exaggerated. Indeed it is our contention that, even those bundles that impact on firm performance play only a relatively modest role in terms of explaining overall performance. The implication for HR practitioners is that delivering bundles of HRM practices is insufficient per se. Thus in simple terms our findings indicate that "off-the-shelf" HRM bundles of practices are inadequate. Like Paauwe, 2004 we would argue that our findings reiterate the need for HR practitioners to become more embedded in their organizations' strategic processes so that their offerings are more 
strategically integrated. This means that HR practitioners, in order to maximise the impact they can have within their organisations, should not only select but also adapt strategically relevant HRM practices and thereafter monitor their strategic impact. As such we are arguing that practitioners allow themselves to become more influenced by configurational approaches to HRM and, by the same token, abandon universalistic approaches.

Future research on the effects of HRM-practices would arguably profit from being based on more objective data and more precise modelling. Black and Lynch's (2001) study of the effects of workplace practices, human capital investments and information technology on productivity in US firms by means of an augmented Cobb-Douglas production function, may serve as a model. In addition, merging the survey of US firms with longitudinal data from the Bureau of Census, enabled Black and Lynch to control for omitted variables and endogeneity bias. However, the results of their study provided even less support than ours for the notion that HRM represents a decisive source of enhanced performance.

It may of course be argued, as we ourselves do, that only the more firm-specific variants of the configurational approach are capable of delineating the performance effects of HRM in general. That is a configurational approach may be able to identify firm-specific performance benefits to be derived from collaborative HRM practices. While this is possible we would emphasize the difficulty in testing such approaches empirically without identifying sets of firms that share a very broad range of parameters but which differ in terms of their combinations of HRM-practices. Such an approach is beyond the range of this paper. Nevertheless, this paper does provide an important contribution to the HRM and performance debate, through the finding that the role of HRM in performance is less important than other authors have suggested. In addition, our research suggests that this link is limited to calculative HRM practices. 


\section{References:}

Alcázar, F.M., Fernández, P.M.R. and Gardey, G.S. (2005). "Researching on SHRM: An analysis of the debate over the role played by human resources in firm success." Management Revue, 16(2), 213-241.

Applebaum, E. and Batt, R. (1994), The New American Workplace: Transforming Work Systems in the United States. Cornell University Press, New York.

Arthur, J. B. (1994), "Effects of human resource systems on manufacturing performance and turnover", Academy of Management Journal, vol. 37, pp. 670-87.

Atkinson, J. (1985). “The Changing Corporation” in D. Clutterbuck (ed.), New Patters of Work, Gower, Aldershot, pp.13-34.

Barney, J. B. (1991), "Firm Resources and substantial competitive advantage", Journal of Management, vol. 17, no. 1, pp. 99-120.

Barney, J. B. (1995), "Looking inside for competitive advantage", Academy of Management Executive, vol. 9, no. 1, pp. 49-67.

Barney, J. B. and Wright, P. M. (1998), "On becoming a strategic partner: The role of human resources in gaining competitive advantage", Human Resource Management, vol. 37, no. 1, pp. 31-46.

Becker, B. E., Huselid, M. A., Pickus, P. S. and Spratt, M. F. (1997), "HR as a source of shareholder value: research and recommendations", Human Resource Management, vol. 36, no. 1, pp. 39-47. 
Becker, B. E. and Huselid, M. A. (1998), "High Performance Work Systems and Firm Performance: A Synthesis of Research and Managerial Implications", Research In Personnel and Human Resource Management., vol. 16, pp. 53-101.

Beer, M., Spector, B., Lawrence, P., Quinn Mills, D. and Walton, R. (1985) Human Resource Management: A General Manager's Perspective, New York: Free Press.

Black, S. E., Lynch, L. M. (2001), "How to compete: The impact of workplace practices and information technology on productivity", Review of Economics and Statistics vol. 83, pp 434-445.

Boselie, J. P., Paauwe, J. and Jansen, P. J. (2001), "Human resource management and performance: lessons from the Netherlands", International Journal of Human Resource Management., vol. 12, pp. 1107-1125.

Bowen, D. E. and Ostroff, C. (2004), "Understanding HRM-Firm Performance Linkages: The Role of the "Strength" of the HRM System", Academy of Management Review, vol. 29, no. 2, pp. 203-221.

Brewster, C. (1995) “Towards a 'European' model of human resource management”, Journal of International Business Studies 26:1-21.

Collins, C. J. and Clark, K. D. (2003), "Strategic Human Resource Practices, Top Management Team Social Networks, and Firm Performance: the Role of Human Resource Practices in Creating Organizational Competitive Advantage", Academy of Management Journal, vol. 46, no. 6, pp. 740-751. 
Collins, C. J. and Smith, K. G. (2006), "Knowledge Exchange and Combination: the Role of Human Resource Practices in the Performance of High-Technology Firms", Academy of Management Journal, vol. 49, no. 3, pp. 544-560.

Delaney J. and Huselid M. (1996). The Impact of Human Resource Management Practices on Perceptions of Organizational Performance Academy of Management Journal, 39 (4), pp. 949-969

Delaney, J. T., Lewin, D. and Ichniowski, C. (1989), Human Resource Policies and Practices in American Firms, U.S. Government Printing Office, Washington Dc.

Delery, J. E. and Doty, D. H. (1996), "Modes of theorizing in strategic human resource management: Tests of universalistic, contingency, and configurational performance predictions", Academy of Management Journal, vol. 39, pp. 949.

d'Arcimoles, C. H. and Henri, C. (1997), "Human Resource Policies and Company Performance: A quantitative approach using longitudinal data.", Organization Studies, vol. 18 , no. 1 , pp. $857-74$.

Ferris, G. R., Hochwarter, B. A., Ronald Buckley, M., Harrell-Cook, G. and Frink, D. D. (1999), "Human Resource Management: Some new directions", Journal of Management, vol. 25 , no. 3 , pp. $385-415$.

Fombrun, G. R., Tichy, N. M. and Devanna, M. A. (1984), Strategic Human Resource Management, John Wiley \& Sons, New York. 
Gooderham, P.N. and Nordhaug, O. (1997), "Numerical flexibility in Norwegian and British firms: Competitive Pressure and Institutional Embeddedness" Employee Relations, vol.19 (6), s. 568-580.

Gooderham, P. N., Nordhaug, O. and Ringdal, K. (1999), "Institutional and Rational Determinants of Organizational Practices: Human Resource Management in European Firms", Administrative Science Quarterly, vol. 44, pp. 507-531.

Guest, D. E. (1997), "Human resource management and performance: a review and research agenda", International Journal of Human Resource Management, vol. 8, no. 3, pp. 263276.

Guest, D. E., Michie, J., Conway, N. and Sheehan, M. (2003), "Human Resource Management and Corporate Performance in the UK", British Journal of Industrial Relations, vol. 41, no. 2, pp. 291-314.

Guthrie, J. P. (2001), "High-involvement work practices, turnover, and productivity: evidence from New Zealand", Academy of Management Journal, vol. 44, no. 1, pp. 180-190.

Huselid, M. A. (1995), "The Impact of human resource management practices on turnover, productivity, and corporate financial performance", Academy of Management Journal, vol. 38, pp. 635-672.

Ichniowski C., Shaw K. and Prennushi G. (1997). The effects of human resource management practices on productivity: a study of steel finishing lines. American Economic Review, 87 (3), pp. 291-313.

Kalleberg, A. L. and Moody, J. W. (1994), "Human resource management and organizational performance", American Behavioral Scientist, vol. 7, pp. 948-962. 
Laursen, K. and Foss, N.J. (2003). New human resource management practices, complementarities and the impact on innovation performance. Cambridge Journal of Economics, 27(2), 243-263.

Legge, K. (1995), "HRM: from compliance to commitment?", in Legge, K. (ed.) Human Resource Management: Rhetoric's and Realities, Macmillan Press Ltd, Hampshire and London, pp. 174-207.

MacDuffie, J. P. (1995), "Human resource bundles and manufacturing performance: organizational logic and flexible production systems in the world auto industry.", Industrial and Labor Relations, vol. 48, pp. 197-221.

Osterman P. (1994). How common is workplace transformation and who adopts it? Industrial and Labor Relations Review, 47 (2), pp.173-188.

Paauwe, J. and Richardson, R. (1997), "Introduction to Special Issues on HRM and performance", International Journal of Human Resource Management, vol. 8, pp. 257-262.

Paauwe, J. (2004), HRM and Performance: Achieving Long Term Viability, Oxford University Press Inc., New York.

Perry-Smith, J. E. and Blum, T. C. (2000), "Work-Family Human Resource Bundles and Perceived Organizational Performance", Academy of Management Journal, vol. 43, no. 6, pp. 1107-1117.

Pfeffer, J. (1994), Competitive Advantages through People, Harvard Business School Press, Boston. 
Pfeffer, J. (1995), "Producing sustainable competitive advantage through the effective management of people", Academy of Management Executive, vol. 9, no. 1, pp. 55-69.

Porter, M.E. (1980). Competitive Strategy: Techniques for Analyzing Industries and Competitors. Free Press, New York

Schuler, R. S. and Jackson, S. E. (2005), "A quarter-century review of human resource management in the US: The growth in importance of the international perspective", Management Review, vol. 16, no. 1, pp. 11-35.

Schuler, R. S. and Jackson, S. E. (1987), "Linking competitive strategies and human resource management practices", Academy of Management Executive, vol. 1, no. 3, pp. 207-219.

Smith P., Tyson S. and Brough S. (2005), HR policies in high performing organisations: UK evidence and a critique of the RBV. Paper presented at the British Academy of Management, Oxford, 2005.

Stavrou, E. T. and Brewster, C. (2005), "The Configurational Approach to Linking Strategic Human Resource Management Bundles with Business Performance: Myth or Reality?", Management Review, vol. 16, no. 2, pp. 186.

Wall, T., Michie, J. Patterson, M., Wood, S., Sheehan, M., Clegg, C. and West, M. (2004).

On the validity of subjective performance measures of company performance. Personnel Psychology, 57:95-118.

Walton, R. E. (1985), "From control to commitment in the in the workplace", Harvard Business Review, vol. March/April, pp. 25-32. 
Wright, P. and McMahan, G. C. (1992), "Theoretical perspectives for strategic human resource management", Journal of Management, vol. 18, pp. 295-320.

Wright, P., McMahan, G. C. and McWilliams, A. (1994), "Human resources and sustained competitive advantage: a resource-based perspective", International Journal of Human Resource management, , pp. 301-326.

Youndt, M. A., Snell, S. A., Jr and Lepak, D. P. (1996), "Human resource management, manufacturing strategy, and firm performance", Academy of Management Journal, vol. 39, no. 4, pp. 836. 
Table 1. The number of firms from each country

\begin{tabular}{lrr} 
Country & $\mathbf{N}$ & $\boldsymbol{\%}$ \\
\hline UK & 638 & 19.5 \\
France & 308 & 9.4 \\
Germany & 386 & 11.8 \\
Sweden & 171 & 5.2 \\
Spain & 202 & 6.2 \\
Denmark & 266 & 8.1 \\
Netherlands & 80 & 2.4 \\
Italy & 65 & 2.0 \\
Ireland & 242 & 7.4 \\
Portugal & 116 & 3.5 \\
Finland & 135 & 4.1 \\
Former GDR & 123 & 3.7 \\
Greece & 97 & 3.0 \\
Austria & 135 & 4.1 \\
Belgium & 204 & 6.2 \\
Northern Ireland & 113 & 3.4 \\
\hline Sum & 3281 & 100.0
\end{tabular}


Table 2. Principal Components factoring of HRM Practices into Strategic HR Bundles in the European Union. Varimax rotation.

\author{
Strategic Human Resource \\ Bundles (Factors) \\ 1. Training monitoring \\ Eigenvalue after rotation: \\ Variance explained (\%):
}

\section{Share-Options}

Eigenvalue after rotation:

Variance explained (\%):

3. Evaluation of HR Dept.

Eigenvalue after rotation:

Variance explained (\%):

\section{Profit-Sharing}

Eigenvalue after rotation:

Variance explained (\%):

\section{Group-Bonus}

Eigenvalue after rotation: Variance explained (\%):

\section{Performance-related pay}

Eigenvalue after rotation:

Variance explained (\%):

\section{Joint HR-line mgt}

responsibility

Eigenvalue after rotation:

Variance explained (\%):

\section{Human Resource Practices in each bundle}

Analyze employee training needs

3.51 Monitor effectiveness of training

5.76 Evaluate training through learning

Evaluate training through behaviours

Evaluate training through results

Evaluate training through reactions

Offer employee share options for

management

Offer employee share options for

3.32 professional staff

Offer employee share options for clerical

5.44 staff

Offer employee share options for manual staff

Performance of HR dept. evaluated on a

systematic basis

Views of top management taken into

3.28 account for evaluation

Views of line management taken into

5.38 account for evaluation

Employee views taken into account for

evaluation

Human resource managers' views taken into account for evaluation

Offer profit sharing options for management

Offer profit sharing options for professional

3.25 staff

5.34 Offer profit sharing options for clerical staff

Offer profit sharing options for manual staff

Offer group bonus for management

2.69 Offer group bonus for professional staff

4.41 Offer group bonus for clerical staff

Offer group bonus for manual staff

Performance-related pay for management

Performance-related pay for professional

2.50 staff

4.10 Performance-related pay for clerical staff

Performance-related pay for manual staff

Responsibility is joint between HR and line management for:

2.40 Compensation and benefits

0.688

3.93

Recruitment and selection

Factor

loadings

0.449

0.880

0.502

0.827

0.762

0.846

0.782

0.952

0.898

0.842

0.822

0.810

0.733

0.716

0.814

0.928

0.930

0.869

0.728

0.883

0.888

0.716

0.655

0.861

0.876

0.677

Training and development

0.750

0.717

Industrial relations 


\section{Communication on}

Strategy

Eigenvalue after rotation:

Variance explained (\%):

9. Communication on

Finance

Eigenvalue after rotation: Variance explained (\%):

10. Employee involvement

Eigenvalue after rotation:

Variance explained (\%):

\section{Communication on organization of work}

Eigenvalue after rotation:

Variance explained (\%):

12. Career development

Eigenvalue after rotation: Variance explained (\%):

\section{Wider-jobs}

Eigenvalue after rotation:

Variance explained (\%):

\section{Communication to} management

Eigenvalue after rotation:

Variance explained (\%):

15. Downsizing methods Eigenvalue after rotation: Variance explained (\%):
Staff reduction/expansion

0.666

Professional staff briefed about strategy $\quad 0.748$

2.29 Clerical staff briefed about strategy 0.890

3.76 Manual staff briefed about strategy 0.854

Professional staff briefed about finance $\quad 0.766$

2.27 Clerical staff briefed about finance 0.850

3.72 Manual staff briefed about strategy finance $\quad 0.812$

Communication through team briefings $\quad 0.634$

Employee ideas communicated directly to

2.25 senior management

Employee ideas communicated through the

3.69 immediate supervisor

Employee ideas communicated through

workforce meetings

Employee ideas communicated through the use of team briefings

Professional staff briefed about organization of work

Clerical staff briefed about organization of

2.20 work

Manual staff briefed about strategy

3.60 organization of work

Regularly use formal career plans

0.559

2.18 Regularly use succession plans 0.488

3.57 Regularly use planned job rotation $\quad 0.540$

Regularly use high flier schemes

0.714

Regularly use international experience

schemes

0.657

Jobs made wider for management $\quad 0.708$

2.16 Jobs made wider for professional staff 0.777

3.54 Jobs made wider for clerical staff 0.746

Jobs made wider for manual staff 0.616

Management briefed about strategy $\quad 0.551$

1.87 Management briefed about finance 0.681

Management briefed about organization of

3.07 work

0.631

Staff decreased by voluntary redundancy $\quad 0.741$

1.62 Staff decreased by redeployment 0.734

2.65 Outsourcing used instead of staff reduction $\quad 0.650$ 
Table 3. Logistic regression analysis of $15 \mathrm{HR}$-bundles on firm performance $(\mathrm{N}=3,281){ }^{\text {a }}$

Calculative bundles

1. Training monitoring

2. Share-options

3. Evaluation of HR Dept.

4. Profit-sharing

5. Group-bonus

6. Performance related pay

Collaborative bundles

7. Joint HR-Mgt

8. Communication on strategy

9. Communication on finance

10. Employee involvement

11. Communication on organisation of work

14. Communication to management

Intermediary bundles

12. Career development

13. Wider-jobs

15. Downsizing methods

Contingency variables

Lnsize

Price important

Quality important

Growing market

Percent unionized

$R^{2}$ (Cox \& Snell):

Marginal effects on $R^{2}$ of: ${ }^{\mathrm{b}}$

Controls:

Industry

Country

Contingency variables

Calculative practices

Collaborative and Intermediary practices
B $\quad$ S.E. $\quad$ Sig. $\quad \operatorname{Exp}(B)$

$\begin{array}{llll}0.117 & 0.042 & 0.006 & 1.124\end{array}$

$\begin{array}{llll}0.231 & 0.039 & 0.000 & 1.260\end{array}$

$\begin{array}{llll}0.163 & 0.039 & 0.000 & 1.177\end{array}$

$\begin{array}{llll}0.273 & 0.043 & 0.000 & 1.314\end{array}$

$\begin{array}{llll}0.229 & 0.040 & 0.000 & 1.258\end{array}$

$\begin{array}{llll}0.073 & 0.040 & 0.065 & 1.076\end{array}$

$\begin{array}{llll}0.057 & 0.039 & 0.148 & 1.058\end{array}$

$\begin{array}{llll}-0.051 & 0.039 & 0.198 & 0.951\end{array}$

$\begin{array}{llll}0.024 & 0.041 & 0.565 & 1.024\end{array}$

$\begin{array}{llll}-0.009 & 0.041 & 0.833 & 0.991\end{array}$

$\begin{array}{llll}-0.037 & 0.039 & 0.342 & 0.963\end{array}$

$\begin{array}{llll}0.058 & 0.040 & 0.149 & 1.060\end{array}$

$\begin{array}{llll}0.192 & 0.041 & 0.000 & 1.211\end{array}$

$\begin{array}{llll}0.075 & 0.039 & 0.055 & 1.078\end{array}$

$\begin{array}{llll}-0.153 & 0.042 & 0.000 & 0.858\end{array}$

$\begin{array}{llll}0.194 & 0.036 & 0.000 & 1.214\end{array}$

$\begin{array}{llll}-0.290 & 0.080 & 0.000 & 0.748\end{array}$

$\begin{array}{llll}0.298 & 0.110 & 0.007 & 1.347\end{array}$

$\begin{array}{llll}0.325 & 0.080 & 0.000 & 1.384\end{array}$

$\begin{array}{llll}-0.002 & 0.002 & 0.346 & 0.999\end{array}$

0.143

0.012

0.043

0.019

0.032

0.012

\footnotetext{
${ }^{\text {a }}$ Binary logistic regression analysis. Results for the control variables, industry, numerical flexibility, and country, are not reported in the Table.

${ }^{\mathrm{b}}$ Marginal effects are estimated as the increment in the $\mathrm{R}^{2}$ by added each set of variables as a second block to the rest of the variables.
} 